\title{
Intelligent Data Mining of Computer-Aided Extension Residential Building Design Based on Algorithm Library
}

\author{
Gao Zhihui ${ }^{1,2,3,4}$ and Zou Guangtian (i) $)^{1,3,4}$ \\ ${ }^{1}$ School of Architecture, Harbin Institute of Technology, Harbin, China \\ ${ }^{2}$ School of Architecture, The City College of Jilin Jianzhu University, Changchun, China \\ ${ }^{3}$ Architectural Planning and Design Institute, Harbin Institute of Technology, Harbin, China \\ ${ }^{4}$ Heilongjiang Key Laboratory of Science and Technology of Human Settlements in Cold Region, \\ Ministry of Industry and Information Technology, Harbin, China
}

Correspondence should be addressed to Zou Guangtian; zougt@hit.edu.cn

Received 27 November 2020; Revised 10 December 2020; Accepted 20 December 2020; Published 18 February 2021

Academic Editor: Wei Wang

Copyright (c) 2021 Gao Zhihui and Zou Guangtian. This is an open access article distributed under the Creative Commons Attribution License, which permits unrestricted use, distribution, and reproduction in any medium, provided the original work is properly cited.

In recent years, with the development of construction industry, more scientific, systematic, fast, and intelligent calculation methods are needed to coordinate urban development and fierce market competition, and mathematical algorithm library plays an important role in artificial intelligence. Therefore, the author uses computer mathematical algorithm and extension theory to study and analyze the residential building design and intelligent data mining. It is found that the research of the computer-aided expression method of extension building planning is mainly the expression of the input and output system of extension building planning. It includes knowledge representation, system outline design, system flow, and interface expression based on the mathematical database.

\section{Introduction}

Since the development of architectural planning in the late 1960 s, its theory and practice have been quite mature [1]. Although architectural planning started relatively late in China, with the deepening of theoretical research, architectural designers have gradually realized the importance of architectural planning [2]. However, compared with foreign research, China's research on the theory and method of architectural planning is still in its infancy, and it is still not mature. It is even more "exposed in the practice and teaching of architectural planning" [3]. The traditional architectural design methods based on the individual experience, intuition, judgment, and inspiration of the architects simply cannot meet the requirements of modern society [4]. At present, China is in the process of rapid urbanization, and the amount of construction is much larger than other times. Every architect is facing a heavy design task [5]. There is always a problem in the process of architectural design: designers constantly find many contradictions and innovations in the process of architectural design practice and theoretical research [6]. There is an urgent need for effective methods of data collection, data management, data mining, and knowledge discovery suitable for databases.

In recent years, with the development of the domestic construction industry, the system involved in decisionmaking has become more and more complex due to the large-scale construction project and the diversification of its functions. The strategy of human brain generation alone has become powerless [7]. The United States, Britain, and Japan are in the forefront of research in the field of architectural planning and have formed their own systematic theories and methods. At present, the domestic theoretical and methodological research in the field of architectural planning is mostly based on the research of the United States and Japan [8]. The developing digital architectural design technology has certain advantages in adapting to the complex, changeable, and fast design environment under the existing 
social conditions, but it cannot replace the architect to think intelligently and make the thinking process of architectural design scientific and regular [9]. More is to rely on the aura of the mind to solve the problem. Perceptual thinking is often difficult to understand and master and more difficult to record and promote. However, the vast amount of data accumulated far exceeds the ability of people to analyze and use data. Similarly, in the field of architectural planning, there is also a large amount of data and knowledge, such as building codes, drawings, network data, and architectural books. Therefore, the combination of extenics, architecture, and innovation is a meaningful combination, which has given birth to a new concept-extension architectural design innovation [10].

With the rapid development of China's construction industry and the continuous improvement of the level of architectural design, there are more and more aspects to be considered and dealt with in the design of buildings, and the problems faced are becoming more and more complicated. Nowadays, a large number of new buildings have been built up like mushrooms, and the huge information has been updated, which makes the architects dazzled and unprepared. In ancient and modern China and abroad, human beings also produced a large amount of data and knowledge while carrying out construction activities. In view of the "constructive destruction" in the current building environment and the "construction waste" that was built and demolished, the architectural planning is a comprehensive consideration of the use of the entire building and social, economic, and environmental benefits. We need to constantly find problems and put forward solutions to improve the quality of architectural design and provide a reasonable scientific basis for architectural design [11]. Then, the most closely related to the architect is the first plan, which provides scientific and logical design basis for the architectural design after the general plan is established [12]. Since its establishment, it has been highly appraised by scholars at home and abroad and has also carried out research and practice in many fields. The process of architectural design is called "black box" because its thinking process lacks scientific expression [13].

This paper presents a computer-aided extension housing model, which is a new model of intelligent data mining algorithm for architectural design.

In summary, our contributions are as follows:

(1) This paper presents a new model for computer-aided extension housing

(2) The model is widely applicable in the environment of computer-aided extension housing, and it has high applicability for most intelligent data mining algorithms in architectural design

(3) The new model proposed in this paper has higher recognition, better visualization effect, and stronger reliability of operation results

\section{Related Work}

At present, there is no special research on the application of extenics in the field of architectural planning. This paper reviews the literature from three aspects of architectural planning theory, extenics, and computer-aided design. Kondic's Modern Architectural Theory [14] reflects the new achievements of architecture in the combination of humanities, natural sciences, and technological sciences. Kazanasmaz's Diagrammatical Thinking [15] studies the process of conceptual generation from the perspective of human-brain coordination. It plays a guiding role in the early stage of architectural design and does not provide a scientific explanation for the way of thinking and solutions to problems [16]. It comes down to inspiration and creativity and is highly dependent on the experience of the architect. Because of the lack of rigorous scientific derivation methods, this method of solving problems has a large degree of contingency. It is precise because there is no better way to extract the core ideas and methods to solve the problem from the solution of the previous problems, so when there are new problems, there is still no evidence to check. In other words, always pursuing a higher realm is the common goal of the three [17]. In addition, extenics, architecture, and innovation believe that innovation activities are not patents of a few people. As long as the ideas and methods are correct, everyone has the potential to innovate.

Data mining is the discovery of effective, potentially useful information and knowledge in large, obscure, and cluttered data. The earliest origin of foreign architectural planning was CRS, Texas A\&M College. CRS defined the needs of the owners in the early working methods and began planning before design. Chunyan and Wen's "Architectural Planning-Design Guide from Theory to Practice" extends the thinking of architectural planning [18]. Zhou et al. took the planning away from the design and divided the search problems in the early stage of the building design with the solutions to the later architectural design process [19]. Sheng-Yuan et al.'s "Application of Extension in Architectural Design" and "Architectural Design Innovation and Extension Thinking Mode" discusses the application of the extension thinking mode in architectural design [20]. Other architects believe that "architectural planning is the process of research and decision-making so as to determine which problems to be solved by design." Extension planning is a kind of planning from the angle of dealing with contradictions. It uses various tools to deal with contradictions in extenics to plan and forms a planning idea to solve contradictions with formal methods. In this study, computer mathematical algorithm and extension theory are used to study and analyze residential building design and intelligent data mining, and it is found that the research of the computer-aided expression method of expansion building planning is mainly the expression of expansion building planning input-output system. 


\section{Methodology}

The purpose of computer-aided extension architecture planning is to complete extension architecture planning by means of computer technology so as to make full use of the advantages of computer such as a large amount of information storage, fast operation speed, and tight logical thinking and to make up for the weaknesses of one-sidedness and subjective arbitrariness that may be brought about by relying solely on architects or planning teams for planning. The mode of thinking refers to a relatively stable pattern, method, or approach when the subject reflects the object. It is the sum of all the logical forms, structures, and methods used when the subject reflects the object. It is easy to import the data into the relevant analysis and simulation software so as to obtain accurate data analysis results such as green building analysis, energy analysis, fire safety analysis, and specification testing. As a cross-discipline, Extendology provides a new way of thinking, methods, and quantitative and formal description tools for solving contradictions and innovations. In addition, in the fields of cultural relics construction protection, urban planning, architectural design, parametric design, etc., the theory and method of extenics are also introduced, and a large number of doctoral master's thesis papers have been published. Therefore, the task of scientific, rational, and intelligent architectural design innovation is becoming more and more urgent. Architectural design innovation needs to establish a rational, systematic, quantitative, and complementary theory and method, which is the advantage of extenics.

Figure 1 shows the difference in execution time between the Apriori algorithm and the optimization algorithm when the degrees of support are different. As can be seen from the figure, the minimum support is smaller.

Figure 2 shows the difference in execution time when the number of transaction records in the database is different in the case where the minimum support is fixed.

There are obvious differences between Extension Architectural Planning Knowledge Base and Extension Architectural Planning Basic Database. The differences between them can be seen in Table 1. There are differences and connections between them (Table 1).

Are there any rules for architectural design innovation? Is there any way to go? Extenics gives us a clear answer. How to collect and analyze relevant information quickly and efficiently and logically expand and converge in the right direction is a problem that needs to be solved. Construction projects under design and construction will also produce a large amount of data and knowledge. If these data are not well preserved, it will also be a huge loss for the follow-up architectural design work. Based on extension theory and tools, this paper explores the inspiration bursting mechanism of architectural design innovation by means of formal description tools combining mathematical logic and dialectical logic. From a unique perspective, it provides people with a way to understand the relevant factors of architectural design innovation and establishes a scientific and rational road to innovation so that the idea of "everyone can innovate" is no longer a myth and has great philosophical, scientific, and methodological significance. It provides the possibility for digitalization and computerization of architectural design.

After starting the Hadoop cluster, each time, kill a certain number of data nodes, then run the Chinese hotspot extraction algorithm after MapReduce culture, record the running time of the cluster, and finally calculate the acceleration ratio of each cluster experiment according to the definition of the relative acceleration ratio formula mentioned above, and the curve is drawn in Figure 3.

Relevant knowledge is the knowledge that represents the relationship between things. The correlation between information elements is represented by the relevant knowledge among information elements, and the related knowledge is expressed by the following equation:

$$
-\frac{\mathrm{d} C}{\mathrm{~d} t}=v=k H=k K[C](1+K[C]) .
$$

Implicative knowledge is the knowledge that expresses the relationship between things. Implicative knowledge is represented by the following equation:

$$
\ln \left(\frac{C_{D}}{C}\right)=K t .
$$

Extensible knowledge is the knowledge that represents the result of the combination or decomposition of things. Extensible knowledge is represented by the following equation:

$$
\frac{\partial}{\partial \tau}\left(\rho_{c} c_{p c} t_{c}\right)=\nabla \cdot\left(\lambda_{c} \nabla t_{c}\right) .
$$

It can also acquire the knowledge of conductivity of conduction objects and characteristics:

$$
I=I_{p v}-I_{0}\left[\exp \left(\frac{V+R_{s} I}{a V_{t}}\right)-1\right]-\frac{V+R_{s} I}{R_{p}} .
$$

Therefore, it is necessary to determine the evaluation rules according to the requirements of specific problems in planning and establish appropriate correlation functions, whose formulas are as follows:

$$
D=\frac{k \lambda}{\beta \cos \theta} .
$$

From this, the correlation function values of the three features can be calculated as follows:

$$
\frac{T_{d}}{T_{s}}=\left(\frac{P_{d}}{P_{s}}\right)^{(\gamma-1 / \gamma)} .
$$

EAPDM can provide extension knowledge related to transformation for site planning and help architects solve the problem of site planning for extension architecture (Table 2). 


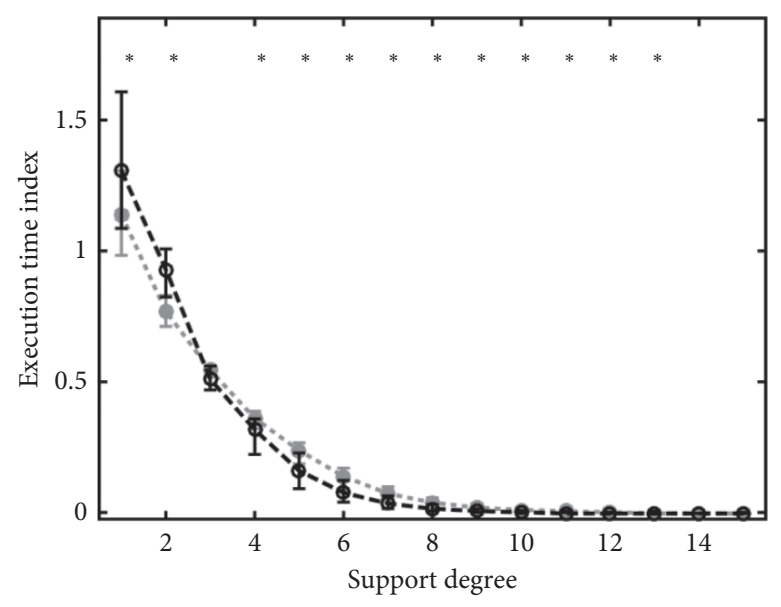

-.. Apriori algorithm

$-\Theta-$ Optimization algorithm

FIGURE 1: Comparison of the execution time of two algorithms with different supports.

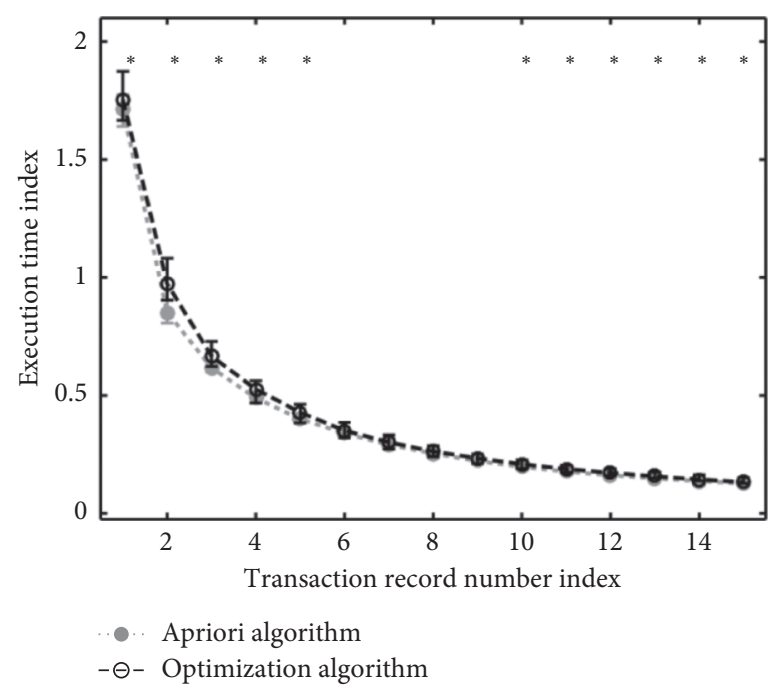

FIgURE 2: Comparisons of execution time between two algorithms under different transaction records.

Table 1: Comparison of Basic Database and Professional Knowledge Base.

\begin{tabular}{|c|c|}
\hline Extension Architectural Planning Basic Database & Extension Architectural Planning Knowledge Base \\
\hline $\begin{array}{l}\text { Store a large amount of data and a small amount of integrity } \\
\text { conditions }\end{array}$ & $\begin{array}{c}\text { Storage of a large number of facts, planning laws, and a large number of } \\
\text { integrity constraints }\end{array}$ \\
\hline Simple structure and few data types & Complex structure and many data types \\
\hline anager & Expert update \\
\hline Ind frequently modified & Data are inaccurate and not often mod \\
\hline facts & Representation of fa \\
\hline ent facts & Managing facts, rules, and constraints \\
\hline Poor reasoning ability & Strong reasoning ability \\
\hline
\end{tabular}

The outline design of the computer-aided extension architecture planning system: constructing a reasonable system architecture is the basis and technical guarantee for the normal work of the computer-aided extension architecture planning system. Architectural planning, extenics, and artificial intelligence have similarities among the three thinking modes. We hope to find a fit point through the comparison and analysis of the three thinking modes so as to make computer-aided extension architectural planning possible. Parameterization defines 


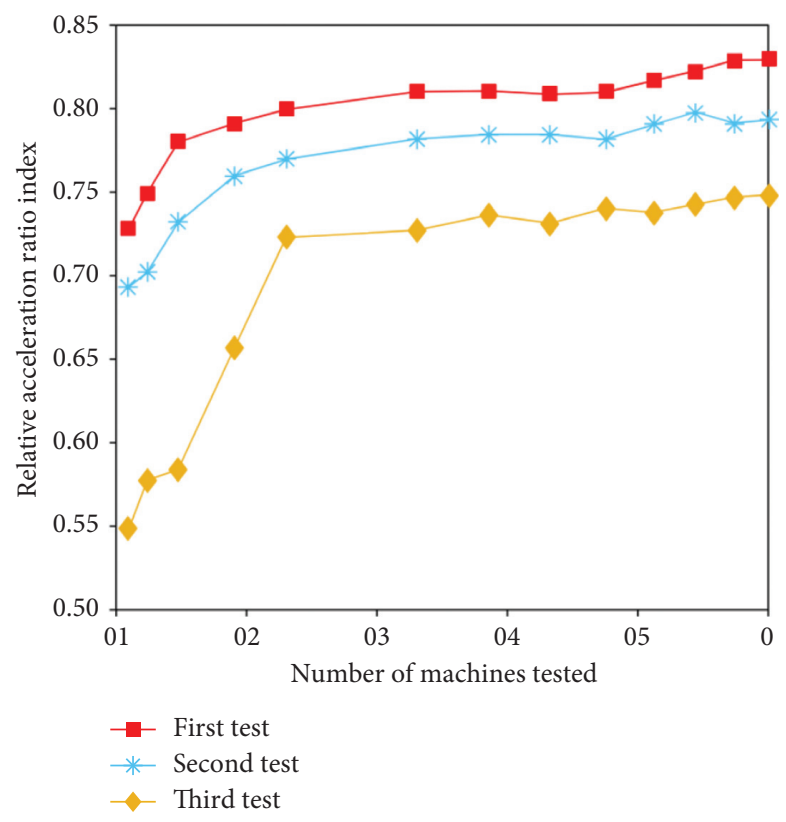

Figure 3: The Hadoop cluster performance acceleration ratio chart.

TABLE 2: Extension mining method for extension building site planning.

Extension building site planning

Content

The main mining methods used in this paper

Type

Location of project base

Cluster mining and extension knowledge mining for EAP knowledge base

Site selection

Various functions and facilities of the site content

Site layout The relation and organization of functional distinction in the site

\begin{tabular}{lcc}
\hline Site traffic & $\begin{array}{c}\text { Traffic and parking } \\
\text { Pedestrian traffic and evacuation }\end{array}$ & $\begin{array}{c}\text { Conduction mining and extension knowledge mining oriented to } \\
\text { EAP knowledge base }\end{array}$ \\
\hline $\begin{array}{l}\text { Site } \\
\text { landscape }\end{array}$ & $\begin{array}{c}\text { Landscape renovation in the site } \\
\text { Integration of architecture and landscape }\end{array}$ & Extension knowledge mining for EAP knowledge base \\
\hline
\end{tabular}

the relationship between things by establishing a relationship between variables and outputs to form a derivative relationship. Problems encountered in the process of architectural design can be solved through quantitative modeling. Data mining can be understood as a knowledge discovery process that acquires knowledge from a large amount of data. It is also a decision support process that can quickly and accurately mine the knowledge behind a large amount of data. The research on the theory and method of extension architectural design innovation can promote the expansion of architectural design innovation methods and help to promote the improvement of China's architectural design innovation level. It uses a series of ideas and methods that contribute to the innovation of architectural design, which can promote the development of new disciplines in architecture. At the same time, the system resource library is described, and the resource classification and data types in the extension building planning resource library are analyzed in detail.
The principle of maximum calculation time is valid, that is, most of the runtime of the platform should be maximized in the calculation process rather than frequently initializing the mapper's communication, for example, as shown in Figure 4.

For the planning of building image, it mainly includes the planning of building volume and shape and the planning of building color and material. Different excavation methods are adopted for different architectural image problems (Table 3).

\section{Result Analysis and Discussion}

The introduction of extension theory has opened up a new research field for architectural planning. The application of the qualitative thinking mode is determined by the nature and characteristics of tasks in this stage, which do not require precise numbers or the results of rigorous mathematical operations. Instead, the focus should be on finding 


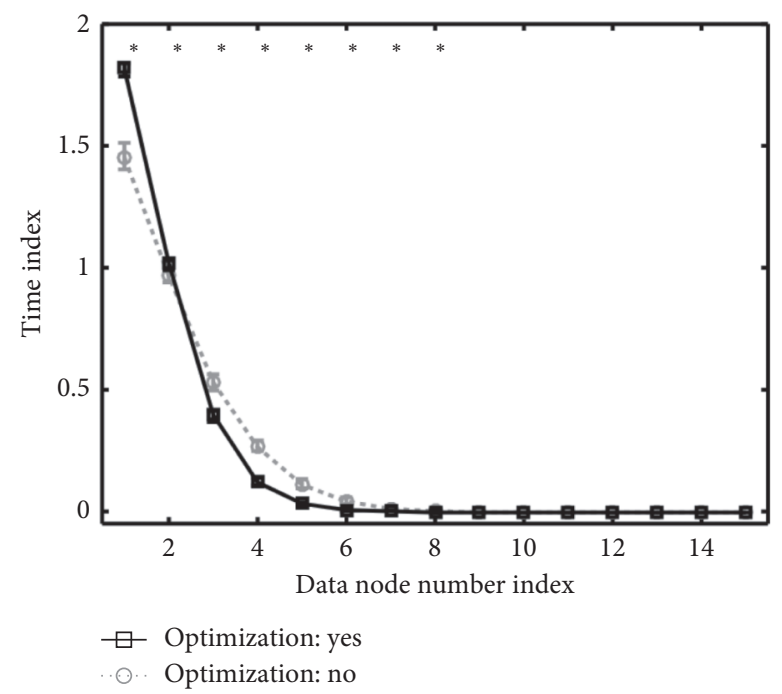

FIgURE 4: MapReduce for collaborative filtering.

TABle 3: The extension mining method for extension architectural image planning.

\begin{tabular}{|c|c|c|}
\hline \multicolumn{2}{|c|}{ Extension architectural image planning } & \multirow{2}{*}{ The main mining methods used in this paper } \\
\hline Type & Content & \\
\hline $\begin{array}{l}\text { Volume and } \\
\text { shape }\end{array}$ & $\begin{array}{l}\text { Building volume } \\
\text { Architectural form }\end{array}$ & $\begin{array}{l}\text { Extension knowledge mining oriented to EAP knowledge base by integrating } \\
\text { various mining means }\end{array}$ \\
\hline $\begin{array}{l}\text { Color and } \\
\text { material }\end{array}$ & $\begin{array}{c}\text { Color and material of the building } \\
\text { surface } \\
\text { Building structural materials }\end{array}$ & $\begin{array}{l}\text { Cluster mining, classification mining, and extension knowledge mining oriented to } \\
\text { EAP knowledge base }\end{array}$ \\
\hline
\end{tabular}

out to the greatest extent what customers are satisfied with and dissatisfied with existing facilities, as well as their most original ideas. The extension model takes the primitive element as the basic element of describing things and uses it to describe information and knowledge. It provides a new theory and method for improving the creative thinking ability and strategy generation technology of artificial intelligence. In the industrial era after the industrial revolution, architectural design developed in the direction of industrialization. The great development of information technology has led to the development of architectural design in the direction of information. The application of information technology in the field of architectural design is becoming more and more extensive. In simple terms, data mining is a process of systematically acquiring knowledge, which includes steps such as data selection, data preprocessing, data transformation, data mining, and pattern evaluation and finally obtains the whole process of knowledge. Extension architectural design innovation introduces scientific and rational system thinking to think about the various factors encountered in the innovation process. This is the guarantee to capture accidental inspiration.

100 users, 200 users, 500 users, and 1,000 users are extracted from Netflix datasets as experimental datasets. The final experimental acceleration is shown in Figure 5.

The planning of extension architecture space form is space form, space closed degree and so on; the planning of space organization is the organization of people flow and the arrangement of relative position (Table 4).

Extenics is based on the premise and basis of innovation in everything in the world: applying its theory to architectural design innovation, expanding the logical category of architectural design innovation, and increasing the composition and systematic operation of rational thinking in architectural design innovation. The content of the method paves the way for more scientific development of architectural design innovation. Data mining is often associated with large databases and computer science and can be achieved through statistics, analytical processing, intelligence retrieval, expert systems, and pattern recognition. Extension building design data mining is a combination of extenics, data mining, and architectural design. It is a process of mining relevant data and knowledge, making extension transformation and acquiring extension knowledge on the basis of database, providing reference knowledge for solving architectural design contradictions and creating new knowledge constantly, and realizing the continuous growth of database and knowledge base. It is hoped that extension formal model expression tools and reasoning methods will be applied to extension architectural planning to promote the intelligent development of computer-aided architectural planning, formalize the creative thinking process in architectural planning, and generate a large number of innovative schemes for selection and development, greatly improving the efficiency of building planning creative schemes. 


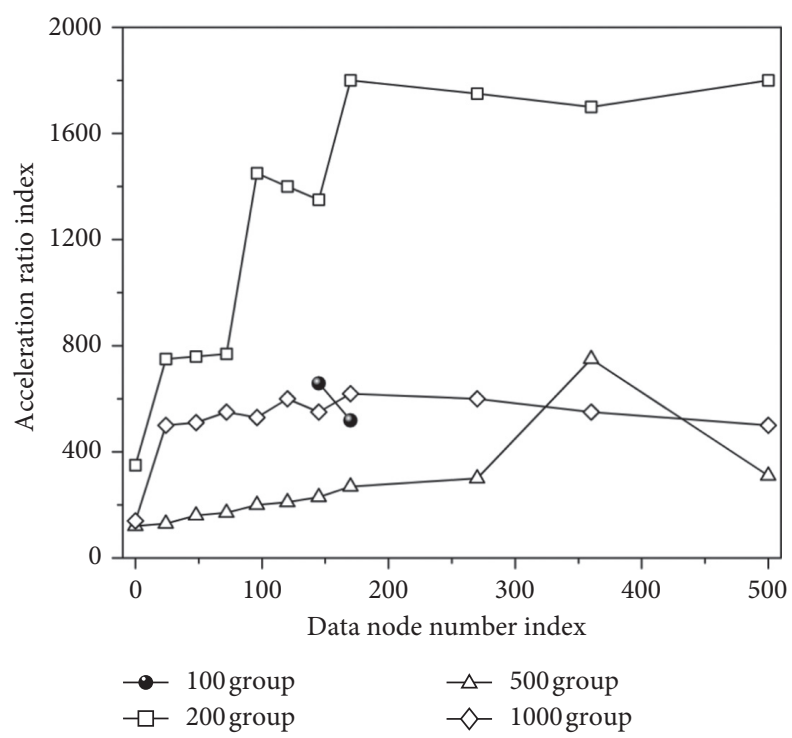

FIgURE 5: Performance acceleration ratio schematic of collaborative filtering algorithm MapReduce.

TABLE 4: The extension data mining method for extension building function planning.

\begin{tabular}{|c|c|c|}
\hline \multicolumn{2}{|c|}{ Extension building function planning } & \multirow{2}{*}{ The main mining method used in the paper } \\
\hline Types of & Content & \\
\hline Spatial content & $\begin{array}{c}\text { Function and area ratio of each function } \\
\text { Effective use of space, "multiple use of } \\
\text { space", etc. }\end{array}$ & Cluster mining and extension knowledge mining for EAP knowledge base \\
\hline $\begin{array}{l}\text { Spatial } \\
\text { organization }\end{array}$ & $\begin{array}{l}\text { Relationship between functions } \\
\text { Traffic stream organization }\end{array}$ & $\begin{array}{l}\text { Cluster mining, conduction mining, and extension knowledge mining for } \\
\text { EAP knowledge base }\end{array}$ \\
\hline
\end{tabular}

After testing on the Hadoop cluster with the above test samples of $300 \mathrm{M}$ and $580 \mathrm{M}$, respectively, the performance acceleration ratio is shown in Figure 6.

There are many innovation objectives and conditions, and the extension innovation model is as follows:

$$
V_{\mathrm{PV}}=\frac{N}{\lambda} \ln \left(\frac{I_{s c}-I_{P V}+\mathrm{MI}_{0}}{\mathrm{MI}_{0}}\right)-\frac{N}{M} R_{s} I_{\mathrm{PV}}
$$

According to different numbers, simple correlation is usually used to establish different correlation functions for the evaluation of architectural design innovation. For example, correlation functions can be used:

$$
\rho \frac{\overrightarrow{\mathrm{d} v}}{\mathrm{~d} t}=-\nabla p+\overrightarrow{\rho f}+\mu \nabla^{2 \vec{v}}
$$

The frequency of occurrence of itemsets is the number of transactions containing itemsets, referred to as the frequency of itemsets, which supports counting as follows:

$$
I=I_{p h}-I_{o}\left(e^{\left(\left(V+I R_{s}\right) / V_{T} m\right)}-1\right)-\frac{V+\mathrm{IR}_{s}}{R_{s h}} .
$$

In addition to using interest as a tool to prune worthless rules, there are other criteria to measure the value of rules, such as promotion $J$, as follows:

$$
J=J o\left[\exp \left(\frac{q V}{A k T}\right)-1\right]
$$

Assuming $J$ is the number of samples in category Voc, the amount of information needed to classify a given data object is

$$
\mathrm{Voc}=\frac{A k T}{q} \ln \left(\frac{J_{L}}{J_{o}}+1\right) .
$$

Let $T$ be the number of samples belonging to class $J$ in subset $t$. According to the entropy or expected information divided into subsets by alpha, the following formula is given:

$$
\alpha=\frac{\sum\left(t_{j}-t_{j-1}\right)}{T}=\frac{\sum \Delta t_{j}}{T} .
$$

Architectural technology planning includes the conception of space structure, structure and equipment, etc. The technical conception is based on the spatial conception and can also feedback and test the spatial conception. The contents and mining methods of extension architectural technology planning are as follows (Table 5).

The knowledge expression of extension architectural planning mainly classifies and formalizes the related factors of architectural planning. Choosing a concise and efficient extension primitive knowledge representation method can formalize different knowledge in the field of 


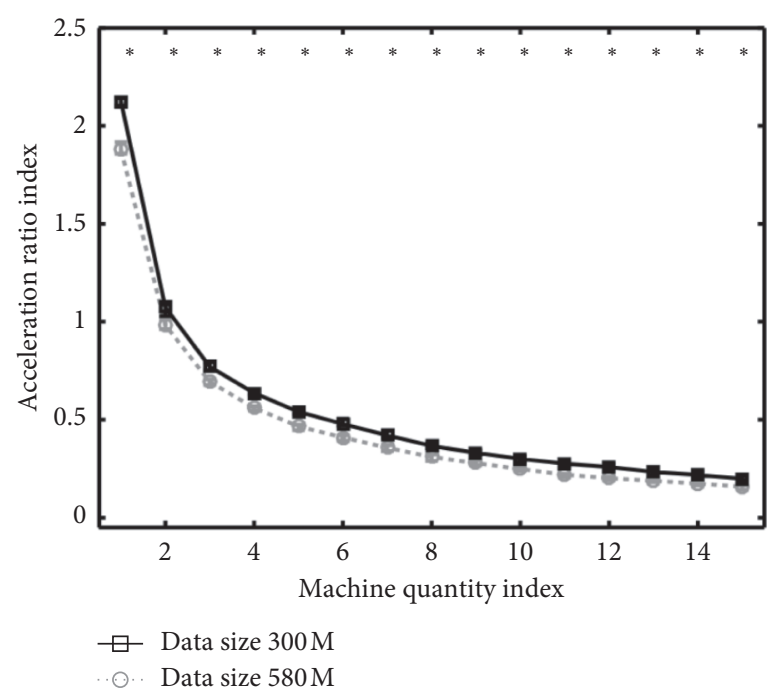

FIgURE 6: Examples of LWLR acceleration ratio.

TABle 5: The extension data mining method for extension architectural technology planning.

\begin{tabular}{|c|c|c|}
\hline \multicolumn{2}{|c|}{ Extension architectural technology planning } & \multirow{2}{*}{ The main mining methods used in this paper } \\
\hline Type & Content & \\
\hline Structural planning & $\begin{array}{l}\text { Selection of structural forms } \\
\text { Effect of structure on modeling }\end{array}$ & $\begin{array}{l}\text { Classification mining and extension knowledge mining oriented to } \\
\text { EAP knowledge base }\end{array}$ \\
\hline $\begin{array}{l}\text { Ecological technology } \\
\text { plan }\end{array}$ & $\begin{array}{c}\text { Taking climate geographical elements as the } \\
\text { leading factor } \\
\text { Taking regional cultural elements as the } \\
\text { leading factor }\end{array}$ & $\begin{array}{l}\text { Extension knowledge mining for EAP knowledge base based on } \\
\text { multiple mining methods }\end{array}$ \\
\hline
\end{tabular}

extension architecture planning, which is directly related to the efficiency of subsequent computer-aided reasoning. The task of this stage is to find out the problem areas at the macrolevel. The modes of thinking adopted are the qualitative mode of thinking and the analytical mode of thinking. A large number of explicit knowledge combined with tacit knowledge possessed by designers themselves and stimulated by the contradiction between demand and technology will form the whole design process. However, most of the current computer-aided architectural design software still focuses on the final drawing, and more is computer-aided drawing. The extension data mining is to perform data mining under a certain contradictory premise, and the mined data are dynamic data that change with time. Therefore, the learned knowledge is changed knowledge, and the knowledge can be expanded. The thinking logic provided by Tektronix is a kind of system thinking. Its elementarybased thinking development framework is an extension of the original innovative thinking mode. This refers to the need to reorganize the traditional architectural knowledge system on the premise of computer utilization to better adapt to the new architectural creation environment.

The MapReduce-based Naive Bayesian algorithm has the following performance test results after running on the Hadoop cluster (Figure 7).

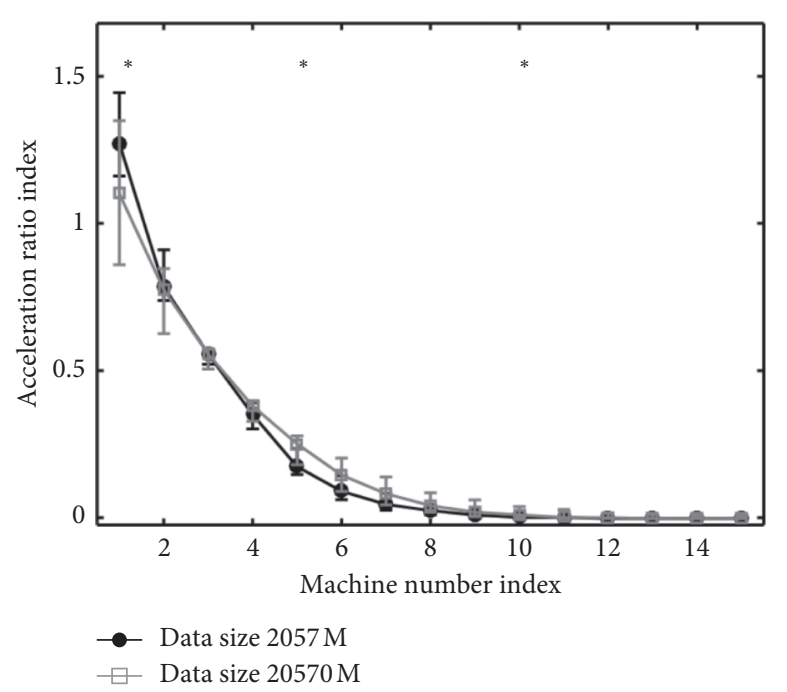

Figure 7: Performance acceleration ratio graph of Naive Bayesian MapReduce.

\section{Conclusions}

Computer-aided expression of extension architecture planning is the intersection of architecture planning, extension science, and computer science. The goal is to promote the intelligent development of computer-aided 
building planning by using the formal model expression tools and reasoning methods of extenics. In order to adapt to the development level of science and technology, architecture must be scientific and digitized step by step and take the road of combining qualitative and quantitative analysis. Extension architectural planning is the product of the intersection of architectural planning and extenics, aiming at solving the problems faced by architectural planning with the way of thinking of extenics. Extension architectural design innovation is not only theoretical innovation but also method innovation, which has both theoretical and practical significance. Using the data mining method designed by extension architecture, potential useful knowledge related to conflict resolution can be found from dynamic, huge, and complex data. Auxiliary building expansion planning is not to replace traditional building planning but to provide effective solutions to contradictions in building planning. It is a general trend to take advantage of the characteristics of high speed, high precision, and large information capacity of computers to do some work instead of architects. With more and more problems involved in architectural design, architects need to use computers to solve these problems.

\section{Data Availability}

The data used to support the findings of this study are available from the corresponding author upon request.

\section{Conflicts of Interest}

The authors declare that they have no conflicts of interest.

\section{Acknowledgments}

This study was supported by the Natural Science Foundation of China (Grant no. 51178132).

\section{References}

[1] I. Van Steenwinkel, B. Dierckx de Casterlé, A. Heylighen, and A. Heylighen, "How architectural design affords experiences of freedom in residential care for older people," Journal of Aging Studies, vol. 41, pp. 84-92, 2017.

[2] S. Verderber, "Residential hospice environments: evidencebased architectural and landscape design considerations," Journal of Palliative Care, vol. 30, no. 2, pp. 69-82, 2014.

[3] Y. Guo, "Research on architecture design of multi-storey residential in west city," Applied Mechanics and Materials, vol. 730, pp. 89-92, 2015.

[4] H. R. Wu and C. P. Hou, "Duplication and innovation: study of the design of Chinese senior residential communities," Advanced Materials Research, vol. 838-841, pp. 2837-2841, 2013.

[5] A. Adewunmi Oluwatayo, E. Ibem, and D. Amole, "Satisfaction of first-time residential clients with architectural services," Journal of Engineering, Design and Technology, vol. 12, no. 3, pp. 316-335, 2014.

[6] L. J. Wang and J. R. Zhang, "Re-interpretation of the typological methods in architectural design of new regionalism-a case of fuyun urban exhibition Hall design in xinjiang province," Applied Mechanics and Materials, vol. 584-586, pp. 74-78, 2014.
[7] A. Hollberg and J. Ruth, "LCA in architectural design-a parametric approach," The International Journal of Life Cycle Assessment, vol. 21, no. 7, pp. 943-960, 2016.

[8] S. Beazley, E. Heffernan, and T. J. Mccarthy, "Enhancing energy efficiency in residential buildings through the use of BIM: the case for embedding parameters during design," Energy Procedia, vol. 121, pp. 57-64, 2017.

[9] R. W. Rukwaro and R. M. Kieti, "Spatial design parameters for residential extensions: the case of Buru Buru estate in Nairobi, Kenya," Architectural Engineering and Design Management, vol. 15, pp. 1-19, 2018.

[10] V. Gana, R. Giridharan, and R. Watkins, "Application of soft landings in the design management process of a non-residential building," Architectural Engineering and Design Management, vol. 14, pp. 1-16, 2017.

[11] M. Budiaková, "Analysis of thermal comfort in flat in new high residential building," Applied Mechanics and Materials, vol. 861, pp. 361-368, 2016.

[12] S. Q. Gan, H. Zhang, and Y. Z. Yang, "The discuss of the development of residential industrialization in the new period," Advanced Materials Research, vol. 912-914, pp. 1813-1816, 2014.

[13] L. Selcová, "The process of hybridization in sustainable urban residential environment," Applied Mechanics and Materials, vol. 820, pp. 33-38, 2016.

[14] S. Kondic, M. Zivkovic, M. Tanic et al., "Analysis of compatibility of contemporary residential housing in nis with current standards in the republic of Serbia," Applied Mechanics and Materials, vol. 725-726, pp. 1244-1251, 2015.

[15] T. Kazanasmaz, İ. E. Uygun, G. G. Akkurt et al., "On the relation between architectural considerations and heating energy performance of Turkish residential buildings in Izmir," Energy and Buildings, vol. 72, no. 72, pp. 38-50, 2014.

[16] M. Fahmy, M. M. Mahdy, and M. Nikolopoulou, "Prediction of future energy consumption reduction using GRC envelope optimization for residential buildings in Egypt," Energy and Buildings, vol. 70, pp. 186-193, 2014.

[17] X. Li, L. Li, and Z. Chen, "Toward extenics-based innovation model on intelligent knowledge management," Annals of Data Science, vol. 1, no. 1, pp. 127-148, 2014.

[18] Y. Chunyan and C. Wen, "Extenics and intelligent processing of contradictory problems," Science \& Technology Review, vol. 32, no. 36, pp. 15-20, 2014.

[19] Y. Zhou, L. Hao, and W. Liu, "Extenics-based study on evaluation of urban community home-care service for the elderly," Procedia Computer Science, vol. 91, pp. 576-580, 2016.

[20] S. Sheng-Yuan, W. Qing, S. Tao et al., "Extenics evaluation of engineering geological zoning of foundation soil in tianjin binhai new area," Journal of Northeastern University, vol. 35, no. 10, pp. 1502-1506, 2014. 